\title{
Trends in energy and macronutrient intakes, body weight and physical activity in female university students (1988-2003), and effects of excluding under-reporters
}

\author{
Penelope M. Warwick ${ }^{1}$ and Jacqueline Reid $^{2}$ \\ ${ }^{1}$ School of Biological, Biomedical and Molecular Sciences, and \\ ${ }^{2}$ School of Mathematics, Statistics and Computer Science, University of New England, Armidale NSW 2351, Australia
}

(Received 22 February 2004 - Revised 24 May 2004 - Accepted 23 July 2004)

\begin{abstract}
The present study investigated trends in reported energy intake, macronutrient intake, physical activity level (PAL) and body weight and effects of excluding under-reporters (UR). Dietary intake and time spent in sixteen activity categories were recorded by 887 female university students (median age 29 years) from 1988 to 2003. Energy expenditure (EE) and PAL were measured using a factorial method. All data collected were self-reported. Individuals with reported EI:EE $<0.76$ were classified as UR. The remainder were classified as nonunder-reporters (NUR). Trends were determined from simple linear regression of median data for each year for the entire cohort (ALL) and for NUR and UR separately, and from multiple regression analysis with the subgroups (NUR and UR) as an additional predictor (BOTH). Prevalence of under-reporting and overweight increased between 1988 and 2003. In ALL and BOTH there were trends to increased body mass, protein intake ( $\mathrm{g} / \mathrm{d}$ and \% energy) and carbohydrate intake (\% energy only) and decreased fat and alcohol intakes (g/d and \% energy). In BOTH there were also increases in reported EI and carbohydrate intake (g/d). None of the trends in NUR was significantly different from those in UR, but some trends in ALL and/or BOTH were not significant when UR were excluded. Trends remaining significant in NUR were increased reported energy intake, protein $(\mathrm{g} / \mathrm{d})$ and carbohydrate $(\mathrm{g} / \mathrm{d})$ intakes, and decreased fat (\% energy only) intake. There were no significant trends in PAL. We conclude that some, but not all, dietary trends were affected by exclusion of UR.
\end{abstract}

Trends: Dietary intake: Under-reporting: Physical activity

For many years, health authorities have recommended dietary changes such as a reduction in fat intake and an increased intake of carbohydrate-containing foods, and favourable trends in dietary composition have been reported (Arnett et al. 2000; Gray-Donald et al. 2000; Hulshoff et al. 2003). Despite this, the prevalence of overweight and obesity has increased in many countries (World Health Organization, 2000). Whether this is due to increased energy intake (EI) or decreased physical activity, or both, is not clear. Some reviews have favoured increased EI (Harnack et al. 2000; McCrory et al. 2000b) or reduced physical activity (Hill \& Melanson, 1999; Jebb \& Moore, 1999), while others have considered that definitive conclusions cannot be made (Jeffrey \& Utter, 2003). Some studies have found increased EI (Anand \& Basiotis, 1998; Kennedy et al. 1999; Cook et al. 2001; Arnett et al. 2002 (women); Nielsen et al. 2002), while others have found no change or reduced EI (Heini \& Weinsier, 1997; Norris et al. 1997: Arnett et al. 2000, 2002 (men); Hulshoff et al. 2003). Results of individual studies on trends in physical activity are also variable (Simmons et al. 1996; Lindquist et al. 2001; Arnett et al. 2002; Barengo et al. 2002; Bruce \& Katzmarzyk, 2002; Rodriguez et al. 2002; Bauman et al. 2003; Lindahl et al. 2003; Talbott et al. 2003). Some of this confusion may be due to difficulties in measuring dietary intake and/or physical activity, and/or failure to identify reports of doubtful validity.

It is well established that the validity of self-reported food intake is uncertain and that EI is generally underreported when compared with energy expenditure (EE); (Black, 2000a; Hill \& Davies, 2001). Misreporting of physical activity level (PAL) may also occur (Lichtman et al. 1992; Jakicic et al. 1998; Irwin et al. 2001), although evidence for this is inconsistent (Macdiarmid \& Blundell, 1998). Under-reporting is more common in overweight than in normal-weight individuals (Macdiarmid \& Blundell, 1998) and under-reporters (UR) appear to have 'healthier' dietary patterns, eating less fat and more protein (expressed as \% total EI) than non-UR (Becker et al. 1999; Rosell et al. 2003). Under-reporting may be due to under-recording (food eaten being forgotten or not

\footnotetext{
Abbreviations: ALL, entire cohort; BOTH, under-reporter and non-under-reporter subgroup; EE, energy expenditure; EI, energy intake; NUR, non-underreporters; PAL, physical activity level; UR, under-reporters.

* Corresponding author: Dr Penny Warwick, fax +6126773 3267, email pwarwick@pobox.une.edu.au
} 
reported) or to under-eating (consuming less food while under study) (Macdiarmid \& Blundell, 1998; Goris et al. 2001). Whatever the cause, under-reporting is a major source of bias in dietary studies, and conclusions may be altered by including UR in the data set (Stallone et al. 1997; Macdiarmid et al. 1998; Becker \& Welten, 2001; Rosell et al. 2003). As the prevalence of under-reporting may be increasing (Hirvonen et al. 1997; Heitmann et al. 2000), trends in dietary intake could be compromised by disproportionate under-reporting, although this has not been widely considered to date.

The aim of the present study was to investigate trends in energy and macronutrient intake, body weight and physical activity in university students studying an optional unit in human nutrition between 1988 and 2003, and to examine effects of excluding UR from the analysis.

\section{Subjects and methods}

\section{Subjects and protocol}

The present study analysed data collected from all ( $n$ 887) non-pregnant, non-lactating female university students undertaking an undergraduate 'interest' (optional) unit in human nutrition at the University of New England (Australia) each year from 1988 to 2003. Students were a mixture of mature-age correspondence students and younger oncampus students. Data were also collected from 199 male students over the same period, but there were small numbers in each year, so the data for men were not analysed for the present paper. The number of female students in each consecutive year from 1988 to 2003 were 50, 47, 44, 31, 33, 32, 46, 42, 38, 48, 80, 65, 83, 82, 92 and 74.

As part of a mandatory practical assignment on dietary assessment, all students enrolled in the unit were required to keep records of habitual dietary intake and physical activity. Dietary records (7d) were kept from 1988 to 1995, reducing to $4 \mathrm{~d}$ from 1996 to 2003 . All records were kept during February or March each year. The record period included at least one leisure (weekend) day. Students were given a booklet containing detailed instructions on the methods to be used and individual assistance was provided as required. P. M. W., from whom a copy of the booklet may be obtained, checked all the records. Except for the length of recording period ( 7 or $4 \mathrm{~d}$ ), the protocol was identical in all years.

The decision to analyse the data was not made until after all the data had been collected. Thus our present sample was not 'representative' and there was no formal recruitment process other than to include data from all students who had completed the assignment. However, as the main purpose of the study was to use existing data to examine effects on trends of removing UR, the lack of representativeness of the sample is not considered to be important.

The retrospective use of the student data in the present study was approved by Human Research Ethics Committee of the University of New England (approval no. HE03/106).

\section{Pattern of activity and energy expenditure}

Each student recorded their activities during the study period to the nearest $1-5$ min on time sheets. Daily EE and PAL were calculated using a factorial method from time spent in sixteen activity categories and their average energy costs relative to BMR as described previously (Warwick, 1989), except for an adjustment to the energy cost allocated to one of the 'on foot' activity categories. Table 1 shows the activity categories used in the present study and their average energy costs. BMR was calculated from body weight measured on the first day of the study using the equations in Table 1 of Schofield et al. (1985). To investigate time spent on physical activity, we analysed data for each of the individual activity categories in Table 1, the sum of time spent in the on foot $(\mathrm{F})$, walking (W) and exercise (E) activities, and the times spent in all activities allocated an energy cost $\geq 4.0 \times \mathrm{BMR}$ $(\mathrm{F} 3+\mathrm{F} 4+\mathrm{W} 3+\mathrm{E} 3+\mathrm{E} 4+\mathrm{E} 5)$ and $\geq 5.0 \times \mathrm{BMR}$ $(\mathrm{F} 4+\mathrm{W} 3+\mathrm{E} 4+\mathrm{E} 5)$.

\section{Energy and macronutrient intakes}

Dietary intake was measured by a combination of the precise weighing and the weighed inventory methods, as reported previously (Warwick \& Busby, 1991). Correspondence students were required to purchase or borrow a set of diet scales (minimum $500 \mathrm{~g}$ capacity with $5 \mathrm{~g}$ divisions). On-campus students were provided with a set of portable electronic scales (2000 $\mathrm{g}$ capacity with $1 \mathrm{~g}$ divisions) although two early cohorts (1988 and 1989) used $500 \mathrm{~g}$ capacity, $5 \mathrm{~g}$ division diet scales. Students who were not able to weigh food consumed away from home described the foods in detail; weights were established later by

Table 1. Activity categories used in the present study and their average energy costs expressed as multiples of BMR

\begin{tabular}{|c|c|c|}
\hline Activity category* & $\begin{array}{l}\text { Activity } \\
\text { category }\end{array}$ & $\begin{array}{c}\text { Energy } \\
\text { cost }^{*}\end{array}$ \\
\hline \multicolumn{3}{|l|}{ Lying and sitting activities } \\
\hline Lying asleep & LA & $1 \cdot 0$ \\
\hline Lying quietly & LQ & $1 \cdot 2$ \\
\hline Sitting quietly & SQ & $1 \cdot 2$ \\
\hline Sitting busy & SB & 1.5 \\
\hline \multicolumn{3}{|c|}{ 'On foot' activities, excluding exercise and sport (F) } \\
\hline $\begin{array}{l}\text { Involving a little walking } \\
\text { or moving around }\end{array}$ & $\mathrm{F} 1$ & $2.5 \dagger$ \\
\hline $\begin{array}{l}\text { Involving some walking and } \\
\text { moving around or active work }\end{array}$ & $\mathrm{F} 2$ & 2.5 \\
\hline $\begin{array}{l}\text { Involving walking or moving } \\
\text { around, and activities that } \\
\text { involve some bursts of } \\
\text { heavy work }\end{array}$ & F3 & $4 \cdot 0$ \\
\hline $\begin{array}{l}\text { Involving very heavy or } \\
\text { strenuous work }\end{array}$ & $\mathrm{F} 4$ & $7 \cdot 0$ \\
\hline \multicolumn{3}{|l|}{ Walking $(\mathrm{W})$} \\
\hline Slowly & W1 & $2 \cdot 0$ \\
\hline Average pace & W2 & $3 \cdot 0$ \\
\hline Fast & W3 & $5 \cdot 0$ \\
\hline \multicolumn{3}{|c|}{ Exercise, sport and leisure activities (E) } \\
\hline Very light activities & E1 & $2 \cdot 0$ \\
\hline Light activities & E2 & $3 \cdot 0$ \\
\hline Moderate activities & E3 & $4 \cdot 0$ \\
\hline Strenuous activities & E4 & $7 \cdot 0$ \\
\hline Very strenuous & E5 & $10 \cdot 0$ \\
\hline
\end{tabular}


a dietitian (P. M. W.). Diets were analysed using a computer package based on Australian food composition tables (NUTTAB; Australian Government Publishing Service, Canberra, Australian Capital Territory, Australia) with additional foods added as required. Reported EI was expressed in $\mathrm{kJ} / \mathrm{d}$ and as an EI level where EI level = reported EI:BMR.

\section{Body weight, height and weight change during the study}

Students were instructed to obtain a set of bathroom scales and to weigh themselves on the first morning of the record period and again on the morning after the end of the record period. The instructions were to record body weight first thing in the morning, in the same clothes, having voided urine, and before drinking or eating anything. Weight change during the study was calculated by the author by subtracting body weight on the final day from that on the first day, and was expressed as weight change in g/d. Students were also asked to report their height in centimetres. Thus all weight and height data were self-reported.

Measurements of body-weight change were used to investigate whether any under-reporting found was due to under-eating or to under-recording (Goris et al. 2001) and as a crude check on our estimation of energy balance (Edholm, 1961). Loss in body weight during a study can be an indication of a reduction in EI. Where there is no under-reporting, the amount of weight lost should be the same as the expected weight loss calculated from energy balance and the energy content of weight loss. Weight losses that are lower than 'expected' can indicate underreporting. In the present study, expected weight loss was calculated from energy balance during the study (reported EI - EE) divided by an approximate energy content of weight loss of $30 \mathrm{~kJ} / \mathrm{d}$ (Saltzman \& Roberts, 1995; Goris et al. 2001).

\section{Identification of under-reporters}

Subjects were identified as UR from their reported EI:EE using the cut-off value calculated by Black (2000b): subjects with reported $\mathrm{EI}<76 \%$ EE (reported EI:EE < 0.76) were classified as UR. In the present study, the remainder of subjects were classified as nonunder-reporters (NUR). The cut-off values used by Black $(2000 b)$ also identified over-reporters (where reported $\mathrm{EI}: \mathrm{EE} \geq 1 \cdot 24)$. However, the prevalence of over-reporting was very small in the present study $(n 15)$ and there was no significant correlation between the percentage of subjects over-reporting and time $(r 0.299, P=0.261)$; as the purpose of this paper was to investigate effects of excluding UR, over-reporters were included as NUR.

\section{Statistical analyses}

Due to skewed distributions, data for subject characteristics, dietary intake and PAL were expressed as median values and 25 th and 75 th percentiles; differences between NUR ( $n$ 440) and UR ( $n$ 447) were evaluated using the Mann-Whitney $U$ test. Except where noted, data for prevalence of under-reporting and overweight in each year were not skewed, and unpaired $t$ tests and simple linear regression analysis were used to assess differences between NUR and UR and the relevant trends respectively.

To investigate trends in body weight, dietary intake and PAL, we analysed the data in several ways, and have reported the results of each analysis. To investigate trends in the entire cohort (ALL) with no consideration of under-reporting, median values for all subjects in each year were tabulated, with each year allocated a year code (0 for $1988, \ldots, 15$ for 2003); trends were determined by simple linear regression. Expressing the data as median values for each year satisfied normality assumptions. UR and NUR were then identified, and the data for the two subgroups (UR and NUR) were tabulated and analysed separately using simple linear regression, as for ALL. Finally, we used a multiple regression model, with year and group as explanatory variables, to test for differences in trends between NUR and UR and for any common trends for the entire cohort separated into the two subgroups (BOTH). All data manipulation and analyses were done using the MINITAB package, (Minitab Inc., State College, PA, USA). Unless otherwise specified, all significance levels given are two-sided.

The question remains as to whether data for UR should be discarded completely (as for NUR), or whether they should be included and accounted for by multiple regression (as for BOTH), or by some other way. As intakes from UR are biased, and excluding UR may affect conclusions (Stallone et al. 1997; Macdiarmid et al. 1998; Becker \& Welton, 2001; Rosell et al. 2003), we believe that it is not appropriate to use data from the entire cohort (as for ALL), but we included this method as it has often been used in the literature. We were uncertain about using multiple regression analysis. This is a statistically superior way to investigate trends where there are known subgroups, but it assumes valid data in all subgroups, which may not be the case for UR. We have therefore placed most emphasis on trends found in NUR. However, where there are no significant differences in trends between NUR and UR, the possibility remains that trends from the multiple regression $(\mathrm{BOTH})$ analysis are more representative of trends in the general population than trends found in NUR using simple linear regression.

\section{Results \\ Characteristics of the subjects and differences between under-reporters and non-under-reporters}

Table 2 shows the characteristics, EI, EI levels, PAL, energy-adjusted macronutrient intakes and times spent in some activity categories for ALL ( $n$ 887), for NUR ( $n$ 440) and UR ( $n$ 447), and differences between the two subgroups. UR were older, and had a greater body weight, BMI and PAL than NUR. UR also had higher energyadjusted intakes of protein and carbohydrate and lower energy-adjusted intakes of alcohol and fat, with the expected lower intakes of total energy. EI level was significantly lower than PAL in all three groups (ALL, UR and NUR), $(P<0.001$ for all comparisons, using paired Student's $t$ tests on the data for all individuals in 


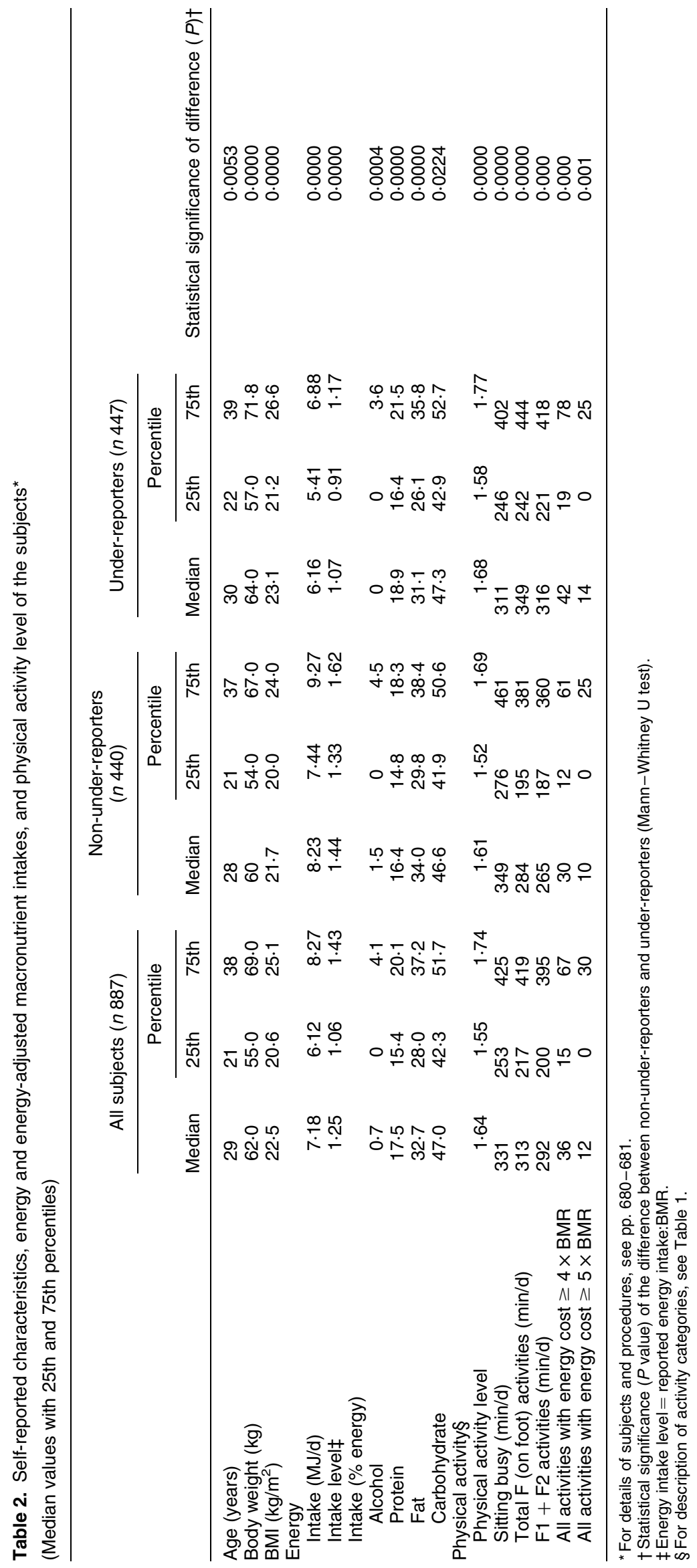


each group and Mann-Whitney $U$ tests on the median data for each year).

There were significant differences between UR and NUR in time spent in several activity categories with UR spending less time sitting busy, and more time in total 'on foot' (F) activities, the majority of which was due to more time in the F1 and F2 categories combined. UR also spent more time in the sum of activities that were allocated energy costs of $\geq 4.0$ and $\geq 5.0 \times \mathrm{BMR}$. There were no significant differences between the two subgroups in time spent asleep, lying and sitting quietly, or in total time spent walking $(\mathrm{W})$ or exercising $(\mathrm{E})$.

\section{Weight loss during the study period}

The individual data for body weight loss during the study were skewed, with median values of zero for all groups. However, mean values indicated that ALL ( $n$ 887) lost 46 (SE 5.2) g/d during the study period, with UR ( $n$ 447) losing 62 (SE 7.7) g/d and non-UR ( $n$ 440) losing 29 (SE $6.8) \mathrm{g} / \mathrm{d}$. As the paired Student's $t$ test is robust against departures from normality, particularly for large samples, we used this to examine whether weight losses were significantly different from zero, and they were in all three cases (ALL, non-UR and UR; $P=0.000$ for each comparison). The difference in weight loss between non-UR and UR (even though both median values were zero) was statistically significant using the Mann-Whitney $U$ test $(P=0.004)$ and using the unpaired $t$ test $(P=0.001)$. Mean expected weight losses were: NUR 24 (SE 2.0) g/d (actual weight loss $29 \mathrm{~g} / \mathrm{d}$ ); UR 129 (SE 2.1) g/d (actual weight loss $62 \mathrm{~g} / \mathrm{d}$ ). In UR, the expected weight loss was significantly greater than actual weight loss $(P=0.000$, Mann-Whitney U test and paired $t$ test). Thus, UR lost more weight while under study than NUR, and lost less weight than expected from their energy balance, suggesting a combination of both under-eating and under-recording in UR. In NUR, actual weight loss was similar to expected loss, suggesting under-eating without under-recording.

Simple linear regression analysis of the mean weight change tabulated for each year ( $n 16$ years) showed a significant increase in weight loss during the study period over time in UR (trend coefficient 3.6 (SE 1.4) g/d per year, $P=0.019$ ), translating to a weight loss of $28 \mathrm{~g} / \mathrm{d}$ in 1988 , increasing to $82 \mathrm{~g} / \mathrm{d}$ by 2003 . In NUR there was no significant change in weight loss with time $(P=0.374)$, translating to weight loss of $16 \mathrm{~g} / \mathrm{d}$ in 1988 and $37 \mathrm{~g} / \mathrm{d}$ by 2003. In this analysis, mean weight change in each year was used because many of the median values for each year were zero.

These weight change comparisons are limited by use of skewed mean rather than median values, unknown accuracy of self-recorded weight changes by subjects (43\% of which were recorded as zero), errors involved in assuming the same energy content of weight change for all subjects (Saltzman \& Roberts, 1995) and by the possibility that the change from $7 \mathrm{~d}$ to $4 \mathrm{~d}$ records in 1996 affected weight change expressed on a per $d$ basis. Inspection of the scatter-plot of weight change against year shows no evidence for this final possibility.

\section{Prevalence of under-reporting and overweight}

Of the 887 subjects, $50.4 \%$ were UR and $25.7 \%$ were overweight $(\mathrm{BMI} \geq 25 \cdot 0)$. There was a significant increase in the prevalence of under-reporting with time (trend coefficient 1.08 (SE 0.36 ) \% per year), increasing from $41.3 \%$ in 1988 to $57.5 \%$ in $2003(P=0.01)$. In the present study, $64.5 \%$ of overweight subjects under-reported compared with $45.5 \%$ of normal-weight subjects, confirming higher levels of under-reporting in overweight subjects. Prevalence of overweight also increased with time (trend coefficient 1.20 (SE 0.20 ) $\%$ per year, $P<0.001$ ), increasing from $15.5 \%$ in 1988 to $33.6 \%$ by 2003 ; however, due to one unusual observation (in 1991, reason unknown) normality assumptions were violated, so this result was not statistically valid. However, re-analysis of the data excluding the unusual observation satisfied normality assumptions and made little practical difference to the result (trend coefficient 1.35 (SE 0.14 ) $\%$ per year, $P<0.001 ; 13.7 \%$ overweight in 1988, increasing to $34.0 \%$ in 2003). Using a test of proportions, the prevalence of overweight was greater in UR than in NUR (32.9 (SE 2.4) v. 18.4 (SE 2.0) $\%$ respectively, $P=0.000)$. However, multiple regression analysis showed no difference between UR and NUR in the trend to increasing prevalence of overweight with time.

Trends in body weight, dietary intake and activity patterns

Table 3 shows trends between 1988 and 2003 for median body weight, BMI, reported EI, PAL, macronutrient intakes, and time spent in some activity categories. Results are shown for ALL, BOTH and NUR. There were no statistically significant differences in trends between NUR and UR, although the difference for PAL was marginal $(P=0 \cdot 059)$.

In ALL and BOTH there were many significant trends. These included increases in body weight, BMI, protein (g/d and \% energy) and carbohydrate intake (\% energy only), and time spent lying asleep and sitting quietly, and decreases over time for alcohol (\% energy only) and fat intakes (g/d and \% energy), and time spent sitting busy and walking average pace. In BOTH (but not ALL) there were also significant increases in EI, in carbohydrate intake $(\mathrm{g} / \mathrm{d})$, and in time spent in $\mathrm{F} 2$ 'on foot' activities. In ALL, but not BOTH, there was a significant increase in time spent in activity categories allocated an energy cost of $\geq 4.0 \times$ BMR. Many of the trends in ALL and/or BOTH were weakened when UR were excluded. The only trends remaining significant in NUR were those for EI, protein and carbohydrate intake ( $\mathrm{g} / \mathrm{d}$ only), fat intake (g/d and \% energy) and time in 'lying asleep' and 'sitting busy' activities.

We do not believe that our trends were affected by changing from 7 to $4 \mathrm{~d}$ records in 1996, as data for the first $4 \mathrm{~d}$ of the $7 \mathrm{~d}$ records were tabulated in 1995, and comparisons between 4 and $7 \mathrm{~d}$ results showed no differences $(P>0.6$ for all comparisons, Mann-Whitney U test; $P>0.2$ for all comparisons, paired $t$ test). In addition, inspection of scatter-plots of the variables against time showed no evidence of differences pre- and post- 1995 .

There were no significant trends with time for age, height, EI level or any of the activity categories not listed in Table 3. 


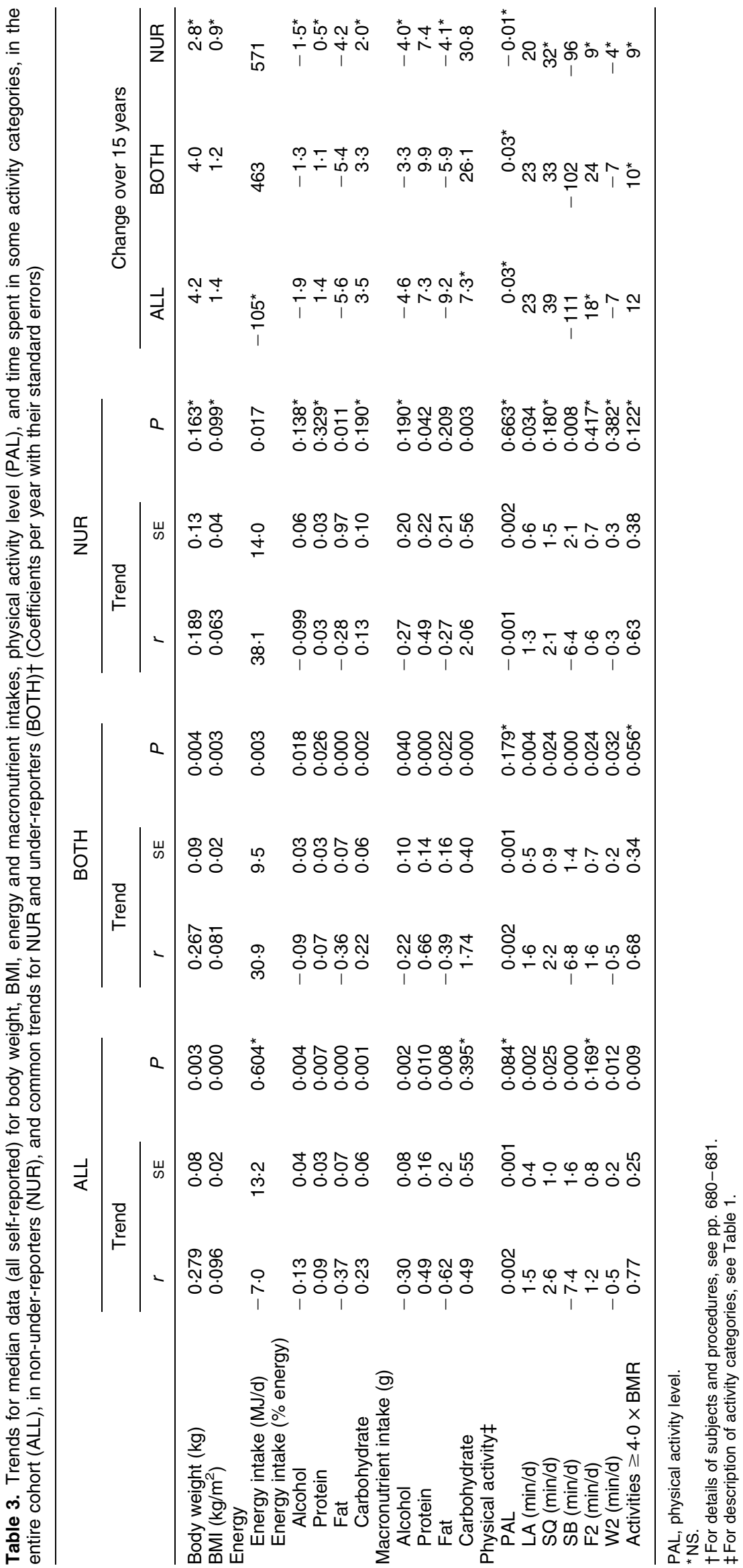




\section{Discussion \\ Prevalence of and trends for overweight and under- reporting}

In our present sample of female university students, we found a significant increase in the prevalence of overweight and an increase in body weight between 1988 and 2003. Despite the lack of 'representativeness' of our sample, and the fact that body weights and heights were self-reported, our rates of overweight (about $15 \%$ in 1988 , rising to $34 \%$ by 2003) are compatible with data from Australian female subjects of similar age: $22 \%$ overweight or obese in 1989 (National Heart Foundation, 1990), 33\% overweight or obese in 1995 (Mclennan \& Podger, 1998) and 35\% overweight or obese in 2000 (Cameron et al. 2003). The increase in body weight in the present study (about $4.0 \mathrm{~kg}$ in the entire cohort, Table 3 ) is also compatible with an increase of $3.7 \mathrm{~kg}$ in Australian women aged 25-34 between 1983 and 1995 (Cook et al. 2001). Thus, our present subjects (university students) appear similar to the general population with regard to body weight status. As found in other studies (Macdiarmid \& Blundell, 1998; Hill \& Davies, 2001) our UR were heavier and had a higher prevalence of overweight than NUR.

We also found an increase in the prevalence of underreporting over time, from $41 \%$ in 1988 to $58 \%$ in 2003 . This trend was expected because of increasing overweight in Australians (Cameron et al. 2003), higher levels of under-reporting among overweight individuals (Macdiarmid \& Blundell, 1998) and because similar trends had already been reported (Hirvonen et al. 1997; Heitmann et al. 2000). We have not compared these results with other studies, as we would expect the prevalence of under-reporting to vary with the subjects studied and the method used to identify UR.

\section{Identification of under-reporters}

As one aim of the present paper was to investigate effects of excluding UR, the quality of the method used to identify UR is important. The most sensitive method is to measure EE and to compare it directly with EI (Black, 2000a), as done in the present paper. This allows identification of UR, who, while appearing to eat reasonable amounts of energy relative to a sedentary lifestyle, still under-report relative to their actual level of activity. It also allows for identification of changes in under-reporting over time if there are also changes in physical activity. The latter is relevant to the present study as, although only marginally significant, PAL tended to increase in UR $(P=0.054$; results not shown in Table 3$)$, but not in NUR $(P=0.663$; Table 3$)$. However, our use of a factorial method to measure EE and classify UR is limited by uncertainty about the validity of activity records and known errors in this method (Durnin, 1978). Some studies have found an over-estimation of activities in some overweight individuals (Lichtman et al. 1992; Jakicic et al. 1998; Irwin et al. 2001) and self-reporting of activity may be subject to similar errors to those in reporting food intake (Macdiarmid \& Blundell, 1998). In the present study, UR had a higher PAL, spent more time in several of the 'active' activity categories and less time sitting busy than NUR (Table 2), but it is not known whether these differences are real or artefacts of misreporting. Thus, some subjects may have been misclassified due to misreporting of activity.

Our use of the EI:EE $<0.76$ to identify UR is also limited by the accuracy of factorial measures of EE. This cut-off for identification of UR was based on the doubly labelled water method (Black, 2000b), and it is generally accepted that factorial measures are less accurate than the doubly labelled water method, especially for individual subjects (Institute of Medicine, 2002; Food and Agricultural Organization, 2004). Factorial measures of EE may also be underestimates (Institute of Medicine, 2002), in which case some of our UR would have been misclassified as NUR and the overall prevalence of under-reporting in our present study would have been under-estimated. This is quite possible, as (unpublished) re-calculation of data for ten non-smoking subjects from a previous study (Warwick \& Baines, 1996) shows that the sixteen-activity-category factorial method used in the present study under-estimated EE by $10 \%$ compared with the doubly labelled water method (9.6 (SE 0.5) v. 10.6 (SE 0.8) MJ/d for factorial and doubly labelled water respectively; $P=0.023$ ), although there was no significant difference between factorial $\mathrm{EE}(9.6(\mathrm{SE} 0.5) \mathrm{MJ} / \mathrm{d})$ and that measured by the intake-balance method (10.2 (SE 0.9) MJ/ $\mathrm{d}, P=0.214)$. The median PAL of 1.64 for our present subjects (Table 2) is also lower than values of about 1.8 found in doubly labelled water studies on women aged 19-50 years (Institute of Medicine, 2002). However, there is no information about activity patterns in the latter report, so the comparability with our present subjects is not known. On the other hand, our PAL is consistent with the 'expected' PAL range (also from doubly labelled water) of 1.6-1.7 for mainly sedentary persons (Black et al. 1996), and the agreement between actual and expected weight loss in NUR indicated reasonable results for energy balance.

McCrory et al. (2002a) have suggested that using the percentage difference between EI and EE to identify UR is technically incorrect when applied to individuals, because it does not take into account errors used in the methods used to quantify EE and EI. However, the cut-off value used by Black $(2000 b)$ to indicate under-reporting (EI:EE < 0.76) and adopted in the present study was calculated after taking such errors into account. On the other hand, taking the errors into account by using the Goldberg equation, as described by Black $(2000 a)$, widens the range of 'acceptable' diet reports and classifies more borderlinereporters as acceptable than the EI:EE $<0.76$ method. We believe that excluding some borderline-reporters (as would have occurred in the present study) would strengthen rather than weaken conclusions about trends in NUR, as there would be a higher level of certainty that the NUR really were NUR.

\section{Trends in physical activity and dietary intake}

In the present study the ALL and BOTH analyses revealed many significant trends, but many trends were weakened by exclusion of UR, suggesting bias from UR (Table 3). 
All of our analyses showed trends to increased time 'sleeping' and decreased time 'sitting busy' over the 15 years, and no statistically significant $(P<0.05)$ change in PAL (Table 3). Excluding UR from the analysis made no difference to conclusions about PAL, but did alter conclusions about trends for time spent in some activity categories (F2, W2 and activities $\geq 4.0 \times$ BMR, Table 3). A marginally significant trend toward increased PAL was found in UR $(P=0.054)$, and significantly more time spent in F2 activities $(P=0.032)$ (results not shown), but, as previously discussed, the validity of self-reported activity in UR is unknown. As these changes were not evident in NUR, we conclude that there was no change in physical activity in the present study, although the decrease in time spent sitting busy (by about $100 \mathrm{~min} / \mathrm{d}$, see Table 3) is an interesting observation for university students.

We were unable to find comparable data in the literature, as most studies have measured leisure or work activities separately, rather than total activity as done in the present study. However, several studies have also reported no secular change in various aspects of activity in various groups (Heitmann et al. 2000; Lindquist \& Bray, 2001; Arnett et al. 2002; Lindahl et al. 2003) or no changes in women (Talbott et al. 2003). One Australian study reported a decline in participation in physical activity between 1997 and 1999, despite increased knowledge about health benefits (Bauman et al. 2003). Although free-living physical activity is difficult to measure (Schutz et al. 2001) and the factorial method is liable to many errors (Durnin, 1978), our increase in prevalence of overweight did not appear to be related to decreased physical activity.

We found a significant decrease over time in \% EI from fat, which was not affected by exclusion of UR. Many other studies have reported decreases in \% EI from fat (Heini \& Weinsier, 1997; Norris et al. 1997; Anand \& Basiotis, 1998; Kennedy et al. 1999; Arnett et al. 2000, 2002; Gray-Donald et al. 2000; Hulshoff et al. 2003) and there appears to be evidence that people have been modifying the fats in their diet in line with dietary recommendations. Whether decreased \% EI from fat is due to reduced fat intake $(\mathrm{g})$, to increased intakes of other macronutrients $(\mathrm{g})$ or to some combination is not clear. Several studies have reported increased carbohydrate intakes ( $\mathrm{g}$; Anand \& Basiotis, 1998; Cook et al. 2001), but results for fat and protein intakes $(\mathrm{g})$ are variable. Some studies have found decreased fat intakes (Norris et al. 1997; Gray-Donald et al. 2000; Cook et al. 2001), while others have found no change (Heitmann et al. 2000) or increases (Anand \& Basiotis, 1998; Kennedy et al. 1999). Similarly, some studies have shown increased protein intakes ( $\mathrm{g}$; Gray-Donald et al. 2000) and others no change (Cook et al. 2001). The fact that expressing macronutrients as $\%$ energy rather than in $\mathrm{g}$ affects trends has been reported previously (Crane et al. 1992). Some of the confusion could also be due to different time-spans investigated. For example, intakes of fat (g; Anand \& Basiotis, 1998) and energy (Kennedy et al. 1999) declined between 1965 and 1990, but increased between 1990 and 1995. In the present study, all of our analyses showed an increase in protein intake (g) between 1988 and 2003, but not all showed decreased fat intake $(\mathrm{g})$. As previously mentioned, we do not believe the ALL analysis to be appropriate, so conclude that carbohydrate intake $(\mathrm{g})$ increased in our present study, as found in another Australian study (Cook et al. 2001). Thus, our decreased \% EI as fat was due to increased EI through increased protein and carbohydrate intakes $(\mathrm{g})$, and not to decreased fat intake $(\mathrm{g})$. Indeed, an increase in EI with time would be expected simply to maintain energy balance with increased body weight at the same level of activity.

Our present trends in EI also varied with the analysis, with significant increases in BOTH and NUR, but not in ALL (Table 3). The lack of increase in ALL was probably due to disproportionate skewing of the results by the very low EI in UR. This illustrates the importance of identifying UR when investigating changes in EI. While several studies have reported no change or declines in EI since the late 1980s (Heini \& Weinsier, 1997; Norris et al. 1997; Hulshoff et al. 2003) despite increases in body weight, others have found increases (Kennedy et al. 1999; Arnett et al. 2002 (women)), including another Australian study (Cook et al. 2001). However, none of these studies identified UR for their analyses.

In conclusion, our present study shows that some trends in activities and dietary intakes are affected by underreporting. When UR were excluded, there were significant increases in energy, and in protein and carbohydrate intakes (g), between 1988 and 2003, with no change in fat intake $(\mathrm{g})$ and a consequent decrease in \% EI from fat. During the same period there was no change in overall PAL. Despite the lack of representativeness of our present sample, and the fact that all data were self-reported, these results support the hypothesis that recent increases in prevalence of overweight are related more to increases in EI than to decreases in physical activity.

\section{References}

Anand RS \& Basiotis PP (1998) Is total fat consumption really decreasing? Nutr Today 33, 171-172.

Arnett DK, McGovern PG, Jacobs DR, Shahar E, Duval S, Blackburn H \& Luepker RV (2002) Fifteen-year trends in cardiovascular risk factors (1980-1982 through 1995-1997). The Minnesota Heart Survey. Am J Epidemiol 156, 929-935.

Arnett DK, Xiong B, McGovern PG, Blackburn H \& Luepker RV (2000) Secular trends in dietary macronutrient intake in Minneapolis-St. Paul, Minnesota, 1980-1992. Am J Epidemiol 152, 868-873.

Barengo NC, Nissinen A, Tuomilehto J \& Pekkarinen H (2002) Twenty-five year trends in physical activity of 30-59-year old populations in Eastern Finland. Med Sci Sports Exerc 34, 1302-1307.

Bauman A, Armstrong T, Davies J, Owen N, Brown W, Bellew B \& Vita P (2003) Trends in physical activity participation and the impact of integrated campaigns among Australian adults, 1997-1999. Aust NZ J Public Health 27, 76-79.

Black AE (2000a) Critical evaluation of energy intake using the Goldberg cut-off for energy intake:basal metabolic rate. A practical guide to its calculation, use and limitations. Int $J$ Obes 24, 1119-1130.

Black AE (2000b) The sensitivity and specificity of the Goldberg cut-off for EI:BMR for identifying diet reports of poor validity. Eur J Clin Nutr 54, 395-404. 
Black AE, Coward WA, Cole TJ \& Prentice AM (1996) Human energy expenditure in affluent societies: an analysis of 574 doubly-labelled water measurements. Eur J Clin Nutr 50, $72-92$.

Becker W, Foley S, Shelley E \& Gibney M (1999) Energy underreporting in Swedish and Irish dietary surveys: implications for food-based dietary guidelines. $B r J$ Nutr 81, Suppl. 2, S127-S131.

Becker W \& Welten D (2001) Under-reporting in dietary surveys - implications for development of food-based dietary guidelines. Public Health Nutr 4, 683-687.

Bruce MJ \& Katzmarzyk PT (2002) Canadian population trends in leisure-time physical activity levels, 1981-1998. Can J Appl Physiol 27, 681-690.

Cameron AJ, Welborn TA, Zimmett PZ, Dunstan DW, Owen N, Salmon J, Dalton M, Jolley D \& Shaw JE (2003) Overweight and obesity in Australia: the 1999-2000 Australian, obesity and lifestyle study (AusDiab). Med J Aust 178, 427-432.

Cook T, Rutishauser I \& Seelig M (2001) Comparable Data on Food and Nutrient Intake and Physical Measurements from the 1983, 1985 and 1995 National Nutrition Surveys. Canberra: Commonwealth Department of Health and Aged Care.

Crane NT, Lewis CJ \& Yetley EA (1992) Do time trends in food supply levels of macronutrients reflect survey estimates of macronutrient intake? Am J Public Health 82, 862-866.

Durnin JVGA (1978) Indirect calorimetry in man: a critique of practical problems. Proc Nutr Soc 37, 5-12.

Edholm OG (1961) Energy expenditure and calorie intake in young men. Proc Nutr Soc 20, 71-76.

Food and Agricultural Organization (2004) Energy in Human Nutrition. Report of a Joint FAO/WHO/UNU Expert Consultation. Food and Agricultural Organization Food and Nutrition Paper no. 78, Rome: FAO.

Goris AHC, Meijer EP \& Westerterp KR (2001) Repeated measurement of habitual food intake increases under-reporting and induces selective under-reporting. Br J Nutr 85, 629-634.

Gray-Donald K, Jacobs-Starkey L \& Johnson-Down L (2000) Food habits of Canadians: reduction in fat intake over a generation. Can J Public Health 91, 381-385.

Harnack LJ, Jeffrey RW \& Boutelle KN (2000) Temporal trends in energy intake in the United States: an ecologic perspective. Am J Clin Nutr 71, 1478-1484.

Heini AF \& Weinsier RL (1997) Divergent trends in obesity and fat intake patterns: the American paradox. Am J Med 102, 259-264.

Heitmann BL, Lissner L \& Osler M (2000) Do we eat less fat or just report so? Int J Obes 24, 435-442.

Hill JO \& Melanson EL (1999) Overview of the determinants of overweight and obesity: current evidence and research issues. Med Sci Sports Exerc 31, Suppl., S515-S521.

Hill RJ \& Davies PSW (2001) The validity of self-reported energy intake as determined using the doubly labelled water technique. Br J Nutr 85, 415-430.

Hirvonen T, Mannisto S, Roos E \& Pietinen P (1997) Increasing prevalence of underreporting does not necessarily distort dietary surveys. Eur J Clin Nutr 51, 297-301.

Hulshoff KFAM, Brussaard JH, Kruizinga AG, Telman J \& Lowick MRH (2003) Socio-economic status, dietary intake and 10 y trends: the Dutch National Food Consumption survey. Eur J Clin Nutr 57, 128-137.

Institute of Medicine (2002) Energy. In Dietary Reference Intakes for Energy, Carbohydrate, Fiber, Fat, Fatty Acids, Cholesterol, Protein and Amino Acids, pp. 93-206 [Food and Nutrition Board and Institute of Medicine, editors]. Washington, DC: National Academy Press.

Irwin ML, Ainsworth BE \& Conway JM (2001) Estimation of energy expenditure from physical activity measures: determinants of accuracy. Obes Res 9, 517-525.

Jakicic JM, Polley BA \& Wing RR (1998) Accuracy of selfreported exercise and the relationship with weight loss in overweight women. Med Sci Sports Exerc 30, 634-638.

Jebb SA \& Moore MS (1999) Contribution of a sedentary lifestyle and inactivity to the etiology of overweight and obesity: current evidence and research issues. Med Sci Sports Exerc 31, Suppl., S534-S541.

Jeffery RW \& Utter J (2003) The changing environment and population obesity in the United States. Obes Res 11, 12S-22S.

Kennedy ET, Bowman SA \& Powell R (1999) Dietary-fat intake in the US population. $J$ Am Coll Nutr 18, 207-212.

Lichtman SW, Pisarska K, Bernman ER, Pestone M, Dowling H, Offenbacher E, Weisel H, Heshka S, Matthews DE \& Heymsfield S (1992) Discrepancy between self-reported and actual caloric intake and exercise in obese subjects. $N$ Engl J Med 327, 1893-1898.

Lindahl B, Stegmayr B, Johansson I, Weinehall L \& Hallmans G (2003) Trends in lifestyle 1986-1989 in a 25- to 64-year-old population of the Northern Sweden MONICA project. Scand J Public Health 61, Suppl., 31-37.

Lindquist CH \& Bray RM (2001) Trends in overweight and physical activity among U.S. military personnel, 1995-1998. Prev Med 32, 57-65.

McCrory MA, Hajduk CL \& Roberts SB (2002a) Procedures for screening out inaccurate reports of dietary energy intake. Public Health Nutr 5, 873-882.

McCrory MA, Suen VMM \& Roberts SB (2002b) Biobehavioural influences on energy intake and adult weight gain. $J$ Nutr $\mathbf{1 3 2}$, 3830S-3834S.

Macdiarmid J \& Blundell J (1998) Assessing dietary intake: who, what and why of under-reporting. Nutr Res Rev 11, 231-253.

Macdiarmid JI, Vail A, Cade JE \& Blundell JE (1998) The sugarfat relationship revisited: differences in consumption between men and women of varying BMI. Int J Obes 22, 1053-1061.

Mclennan W \& Podger A (1998) National Nutrition Survey: Nutrient Intakes and Physical Measurements, Australia 1995. Canberra: Australian Bureau of Statistics.

National Heart Foundation (1990) Risk Factor Prevalence Study Survey No. 3, 1989. Canberra: National Heart Foundation of Australia and Australian Institute of Health.

Nielsen SJ, Siega-Riz AM \& Popkin BM (2002) Trends in energy intake in U.S. between 1997 and 1996: similar shifts seen across age groups. Obes Res 10, 370-378.

Norris J, Harnack L, Carmichael S, Pouane T, Wakimoto P \& Block G (1997) US trends in nutrient intake: the 1987 and 1992 National Health Interview Surveys. Am J Public Health 87, 740-746.

Rodriguez AF, Lopez GE, Guitierrez-Fisac JL, Bangeas BJR, Lafuente UPJ \& Dominguez RV (2002) Changes in the prevalence of overweight and obesity and their risk factors in Spain, 1987-1997. Prev Med 34, 72-81.

Rosell MS, Hellenius MB, de Faire UH \& Johansson GK (2003) Associations between diet and the metabolic syndrome vary with the validity of dietary intake data. Am J Clin Nutr $\mathbf{7 8}$, 84-90.

Saltzman E \& Roberts SB (1995) The role of energy expenditure in energy regulation: findings from a decade of research. Nutr Rev 53, 209-220.

Schofield WN, Schofield C \& James WPT (1985) Basal metabolic rate: review and prediction together with an annotated bibliography of source material. Hum Nutr Clin Nutr 39C, Suppl. $1,1-96$.

Schutz Y, Weinsier RL \& Hunter GR (2001) Assessment of freeliving physical activity in humans: an overview of currently available and proposed new measures. Obes Res 9, 368-378. 
Simmons G, Jackson R, Swinburn B \& Yee RL (1996) The increasing prevalence of obesity in New Zealand: is it related to recent trends in smoking and physical activity? NZ Med J 109, 90-92.

Stallone DD, Brunne REJ, Bingham SA \& Marmot MG (1997) Dietary assessment in Whitehall II. The influence of reporting bias on apparent socioeconomic variation in nutrient intakes. Eur J Clin Nutr 51, 815-825.

Talbott LA, Fleg JL \& Metter EJ (2003) Secular trends in leisuretime physical activity in men and women across four decades. Prev Med 37, 52-60.

Warwick PM (1989) Predicting food energy requirements from estimates of energy expenditure. Aust J Nutr Diet 46, Suppl., S1-S28.

Warwick PM \& Baines J (1996) Energy expenditure in free-living smokers and nonsmokers: comparison between factorial, intake-balance, and doubly labeled water measures. $A m J$ Clin Nutr 63, 15-21.

Warwick PM \& Busby R (1991) Factorial estimation of daily energy expenditure in university students: comparison with recorded energy intake. Aust J Nutr Diet 48, 95-99.

World Health Organization (2000) Obesity: Preventing and Managing the Global Epidemic. World Health Organization Technical Report Series no. 894. Geneva: WHO. 